\title{
Live Bacterial Physiology Visualized with 5 nm Resolution Using Scanning Transmission Electron Microscopy SUPPLEMENTAL INFORMATION
}

Eamonn Kennedy ${ }^{\dagger}$, Edward M. Nelson ${ }^{\dagger}$,Tetsuya Tanaka John Damiano ${ }^{\diamond}$, Gregory Timp ${ }^{\circledR}$

\section{FIGURE S1.}
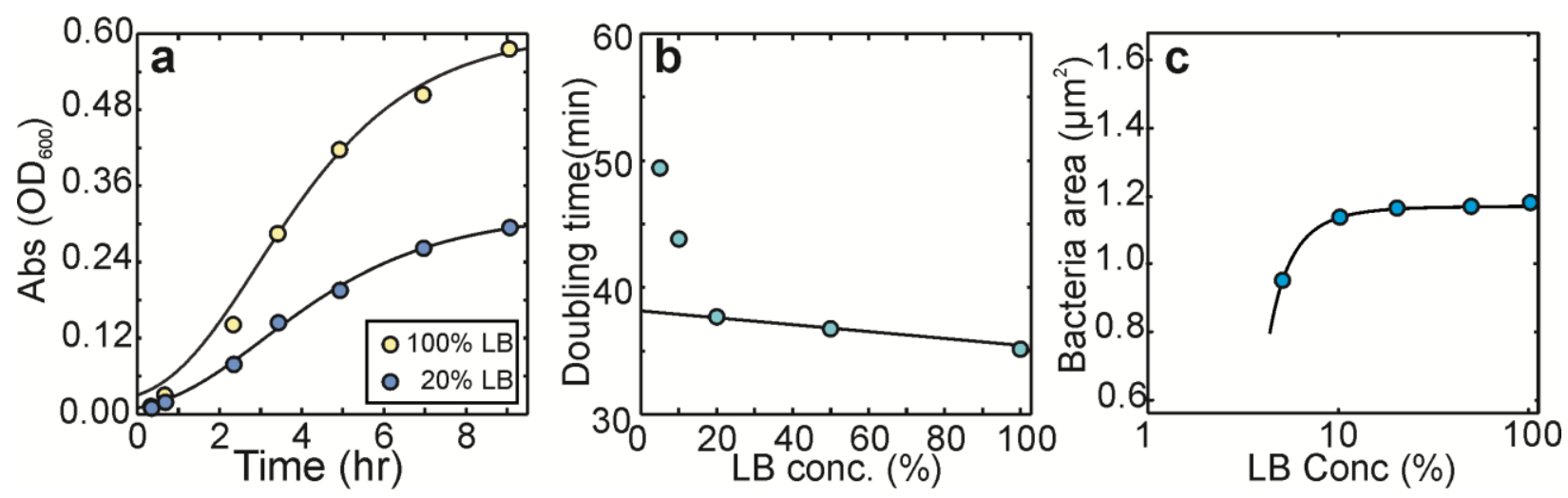

FIGURE S1. Influence of low phosphate media on growth rate. (a) Absorption spectroscopy of bacteria (K12) grown in LB:1× MOPS at different ratios (0.2 and 1) indicated several trends. Reducing LB concentration (which was proportional to the phosphate density of media) resulted in a lower cell count. An $80 \%$ reduction in LB concentration reduced the cell count by $41 \%$ over the course of $8 \mathrm{~h}$. In effect, K12 bacteria can be grown in low phosphate media and still be harvested at a suitably high $\left(0.1<\mathrm{OD}_{600}<0.2\right)$ density, which can be readily reconstituted to higher cell densities. (b) Similarly, the doubling time was retarded in low-phosphate media, but only appreciably for LB concentration $<20 \%$. In contrast, the growth rate in pure MOPS was zero. (c) The cell morphology was unaffected by the concentration of phosphates for LB concentrations $>20 \%$, which was indicated by the consistency of the mean bacteria area measured above this concentration. On the other hand, smaller bacteria were observed for LB concentrations $<20 \%$. Exploiting these properties enabled growth and imaging of bacteria with only minimal phosphate background. 
FIGURE S2.
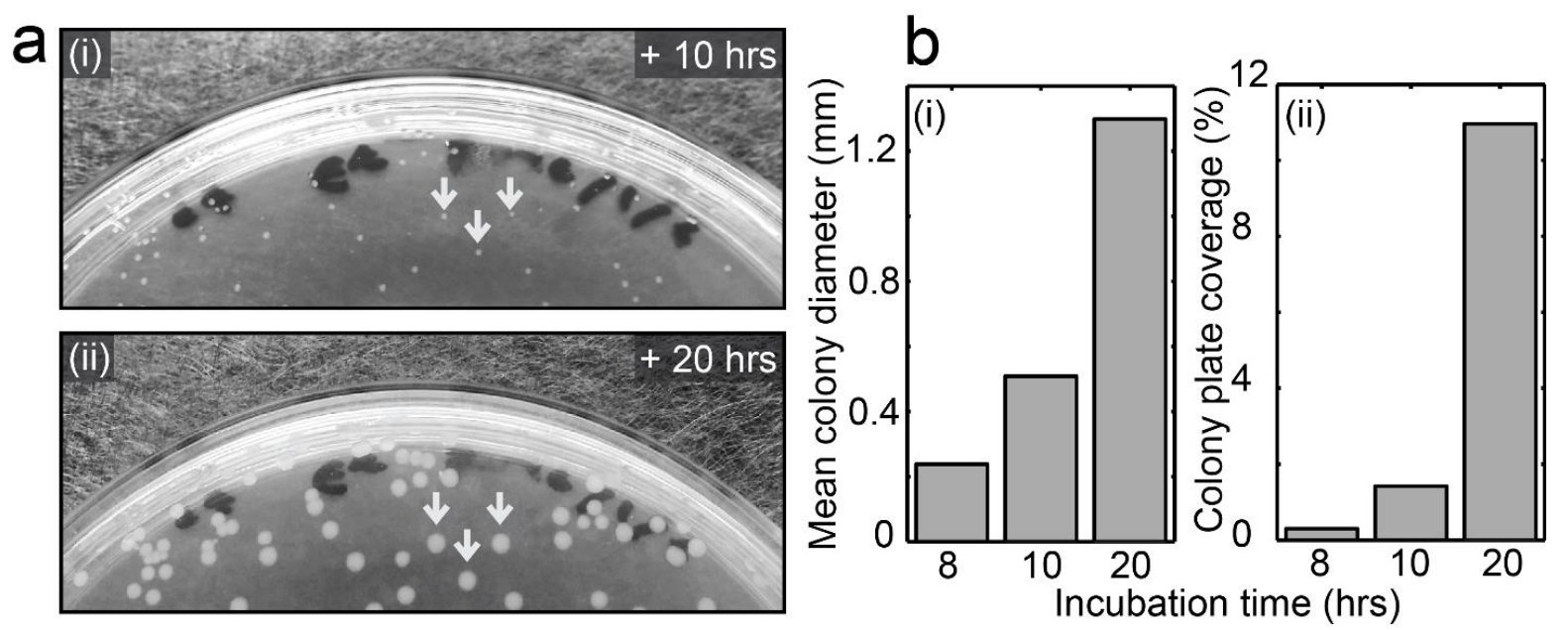

FIGURE S2. Time-dependent analyses of colony growth after $15 \mathrm{~min}$ exposure to $\mathbf{0 . 0 1 \%}$ UA. (a) Typical photographs of plates after (i) 10 and (ii) $20 \mathrm{~h}$ incubation following exposure to $0.01 \%(\mathrm{w} / \mathrm{v})$ UA/MOPS (with identifying labels and the same colony pattern evident in both). Arrows are used to indicate three colonies that show unambiguous growth after low dose UA exposure, indicating physiology was not arrested. (b) Analysis of colony size over the course of a day. The colony diameter (i) and percentage of plate coverage by colonies (ii) increased, with final average colony diameters of $1.3 \mathrm{~mm}$ and coverage of $10.4 \%$ after $20 \mathrm{~h}$. Both of these values were within the statistical error of the control measurements, indicating that short term exposure to low dose UA does not alter subsequent colony growth. 
FIGURE S3.

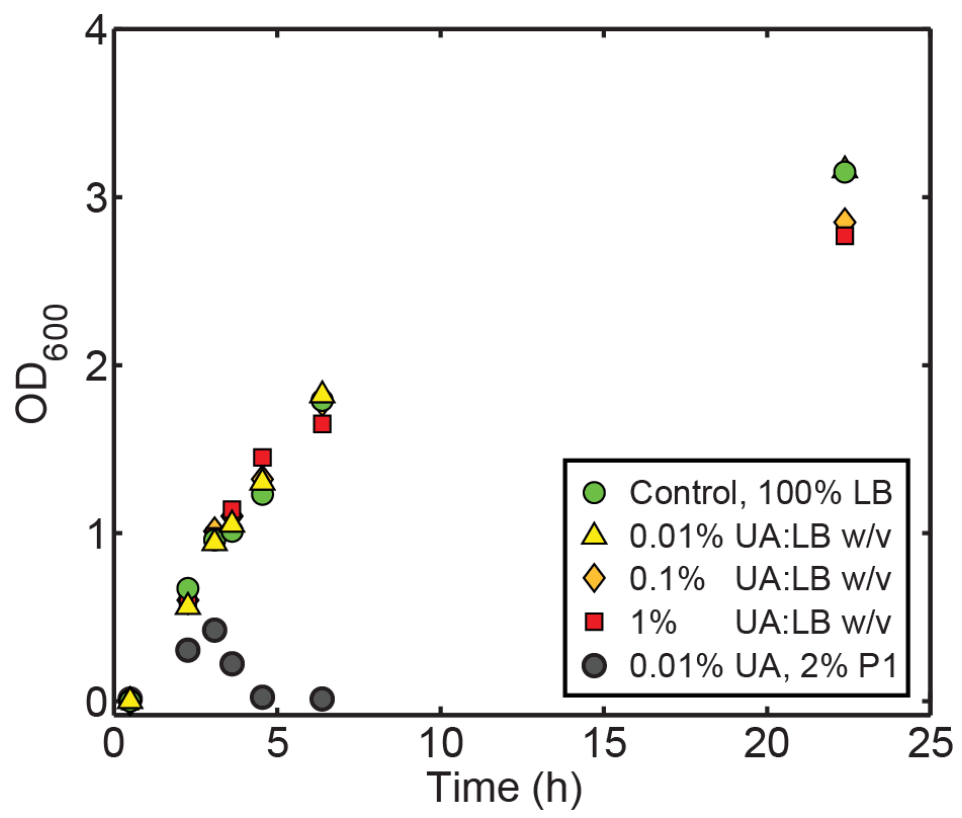

FIGURE S3. Physiology and growth of E. coli after exposure to UA stain. OD 600 measurements over one day of $E$. coli cultured in LB at $37^{\circ} \mathrm{C}$ with varying $(0 \%, 0.01 \%$, $0.1 \%, 1 \%)$ UA supplementation indicated that increasing UA concentration only slightly affected growth rates. UA resulted in a 10\% drop in OD600 between $0 \%$ and $1 \%$ UA after $24 \mathrm{~h}$. Further, $0.01 \%$ UA showed a comparable growth rate to the control after $24 \mathrm{~h}$. The addition of $2 \% \mathrm{w} / \mathrm{v}$ concentrated $\mathrm{P} 1$ lysate along with $10 \mathrm{mM} \mathrm{MgCl}$ and $10 \mathrm{mM} \mathrm{CaCl} 2$ to a control culture in the presence of UA resulted in a significant loss of OD600 over $4 \mathrm{~h}$, indicating cell lysis in the presence of low dose UA stain.

FIGURE S4.
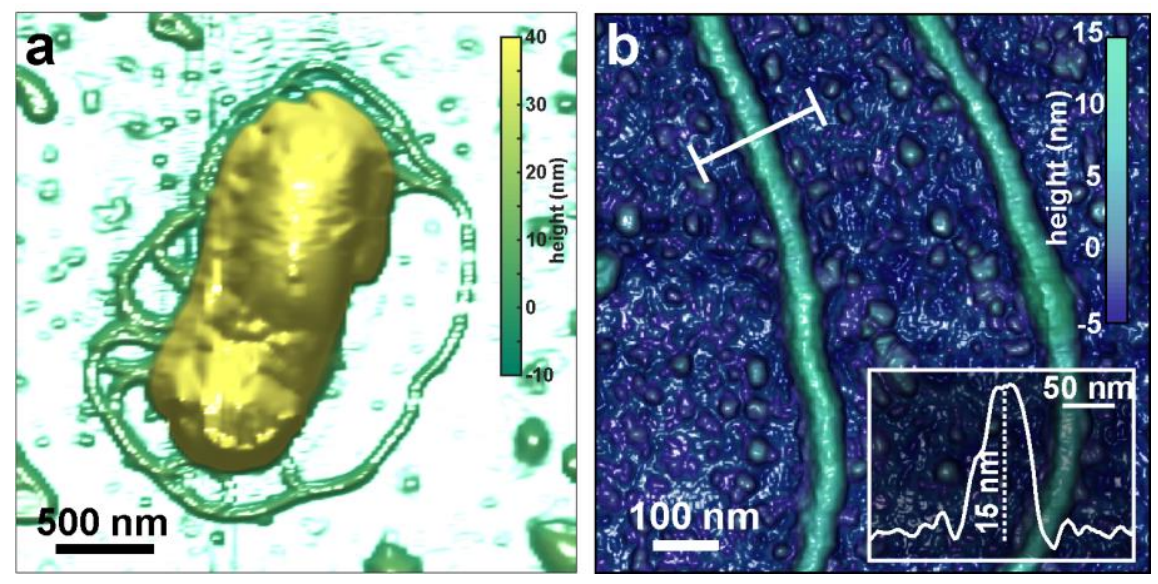

FIGURE S4. AFM profile of E. coli flagella. (a) Consistent with STEM, AFM topography of $E$. coli on mica in air indicates a peritrichous arrangement of flagella $>10$ $\mu \mathrm{m}$ long. (b) Magnified view of the AFM topography with white lines delineating the 
position of line-scans. (Inset) Line-scans through the structure indicate a height of $15 \pm$ $2 \mathrm{~nm}$.

\section{FIGURE S5}
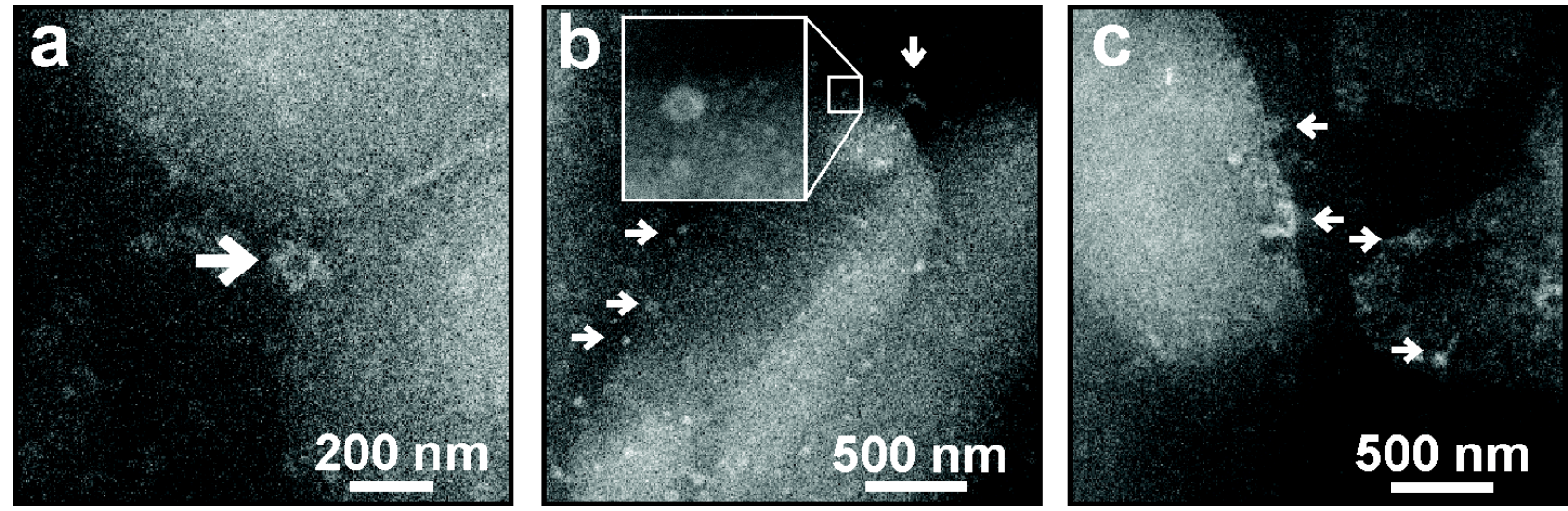

FIGURE S5. Real-time infection of live E. coli at sub-10-nm-resolution. (a) Single viral penetration of the cell wall, imaged at spot size 8 and cumulative dose of $31.3 \mathrm{e}^{-}$ $/ \mathrm{nm}^{2}$ followed by (b) multi-phage infection, maturation and (c) lysis observed with $7.9 \mathrm{e}^{-}$ $/ \mathrm{nm}^{2}, 20000 \times$ in $0.1 \%$ UA/MOPS. Thus, the whole lytic cycle can be observed over time within $\mathrm{LD}_{50}$.

FIGURE S6.

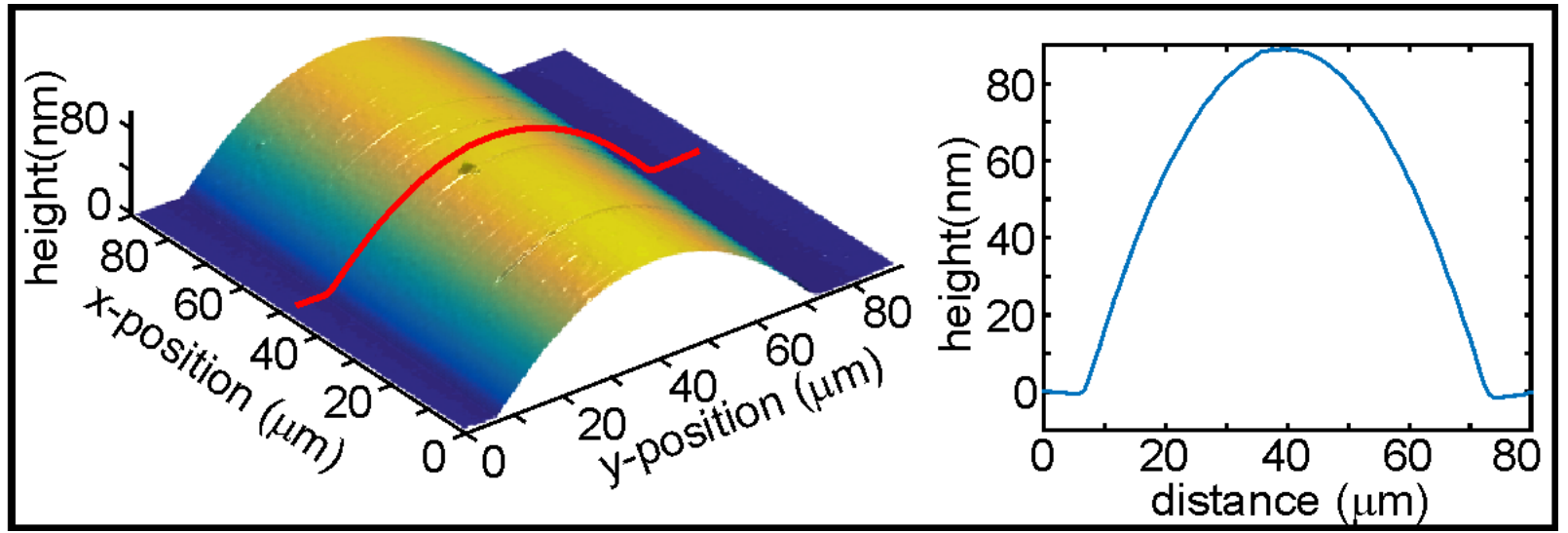

FIGURE S6. The liquid thickness varies across the membrane. AFM togographs taken from E-chips with membranes nominally $50 \mathrm{~nm}$ thick and a liquid layer nominally $2 \mu \mathrm{m}$ thick. 
FIGURE S7.
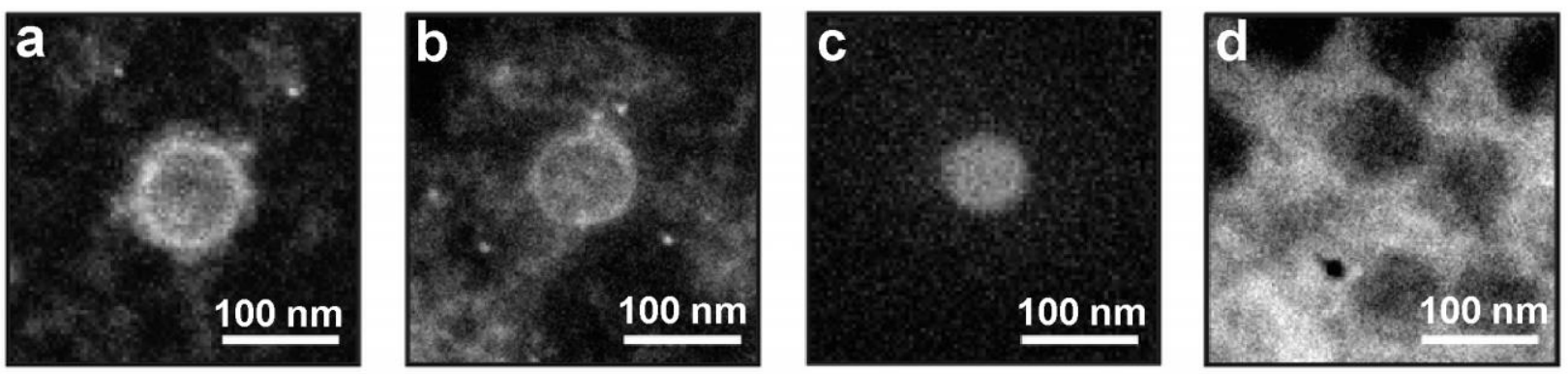

FIGURE S7. UA stained DNA in a P1 capsid. The P1-phage capsids were stained with $0.1 \%$ UA and imaged with spot-size 9 at a $17-36 \mathrm{e}^{-} / \mathrm{nm}^{2}$ dose at $40000-80000 \times$. The contrast within the capsid was attributed to stained DNA. Typical viable conditions used for $\mathrm{P} 1$ consisted of $57000 \times$ and $3.81 \mu$ s pixel dwell time taken at spot size 9 . 